\title{
SDHA mutated paragangliomas may be at high risk of metastasis
}

\section{Dear Editor,}

We report the clinical outcomes of eleven patients with succinate dehydrogenase subunit A (SDHA) germline mutations from three UK tertiary referral centres to highlight a more diverse and expanding clinical spectrum of associated phenotypes. We suggest that SDHA paraganglioma-related disease is not a low-risk condition as first described. Of our six index cases, two developed metastatic disease and a further one had local vascular invasion. One patient developed multiple metachronous disease. Therefore, we believe these patients, like those with $S D H B$ and SDHD mutations, should be part of a surveillance programme.

Paraganglioma (PGL)-associated mutations in SDHA have only been reported in a small number of patients worldwide. There is controversy over the necessity for surveillance screening in these patients, compared to $S D H B$ and $S D H D$, as penetrance is thought to be lower (Benn et al. 2015) and variants exist with uncertain pathogenicity. Initial reports associated $S D H A$ with autosomal recessive causes of juvenile encephalopathy (Leigh syndrome) (Bourgeron et al. 1995) and homozygous mutations in SDHA cause severe neurological dysfunction and cardiomyopathy (Renkema et al. 2015). SDHA mutations have now been associated with phaeochromocytoma and paraganglioma (PPGL) formation in an autosomal dominant manner. SDHA mutations account for only $3 \%$ of cases of familial PGL cases, with presumed low penetrance (Korpershoek et al. 2011) and therefore very little data on clinical features of SDHA-related PPGL exist.

Six index cases were originally diagnosed between 1973 and 2011 and had histologically proven PPGL, who subsequently underwent genetic testing during the course of their follow-up and were confirmed to have an underlying $S D H A$ germline mutation. We performed a retrospective analysis of their notes and describe their clinical outcomes. From these six index cases, cascade genetic testing occurred and identified five further asymptomatic carriers of SDHA mutations. All patients are now being followed up in specialised endocrine clinics and are undergoing annual screening, including annual clinical and biochemical assessment and cross-sectional imaging, although the frequency and modality of imaging differs between centres. To predict the pathogenicity of the DNA variants, the missense variants were investigated in silico using PloyPhen2 and SIFT.

Table 1 provides a detailed summary of the patients described.

The six index patients originally presented were aged 18, 34, 36, 46, 47 and 68 years. Five patients presented with a single lesion at diagnosis: intrathyroidal PGL, mediastinal PGL, phaeochromocytoma and two extraadrenal PGLs. One patient (patient 3) presented with two synchronous lesions: she had a 3-methoxytyramine (3MT)-secreting carotid body tumour and a noradrenalinesecreting thoracic PGL. All patients underwent surgical resection of the primary tumours. Two patients developed recurrence in the surgical bed and both patients went on to develop metastatic disease 16 and 37 years later (patients 8 and 9). One of these two patients (patient 8) also developed an additional five metachronous lesions 7-10 years after original diagnosis. These two cases are described in more detail.

Patient 8 presented aged 46 years with headaches and malignant hypertension $(210 / 130 \mathrm{mmHg})$. Urinary noradrenaline was very raised (Table 1) and imaging confirmed a $5 \mathrm{~cm}$ para-adrenal PGL, which was subsequently resected. He developed a symptomatic recurrence one year later, which was surgically resected. Eight years after his original diagnosis, he presented with symptoms of catecholamine excess and four new lesions were identified and resected. On surveillance imaging three years later, a new non-secretory lesion was identified. Surgical resection was undertaken one year subsequently due to increasing PGL size and plasma catecholamine levels. He remained well with no evidence of further disease on imaging until five years later when rising noradrenaline levels were noted and uptake in the left adrenal bed and in the vertebral body of L4 was

Published by Bioscientifica Ltd 


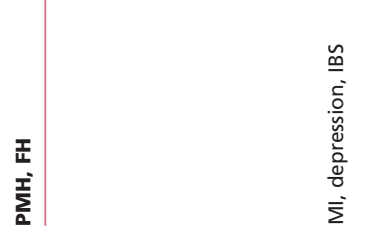

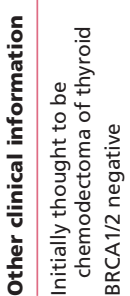
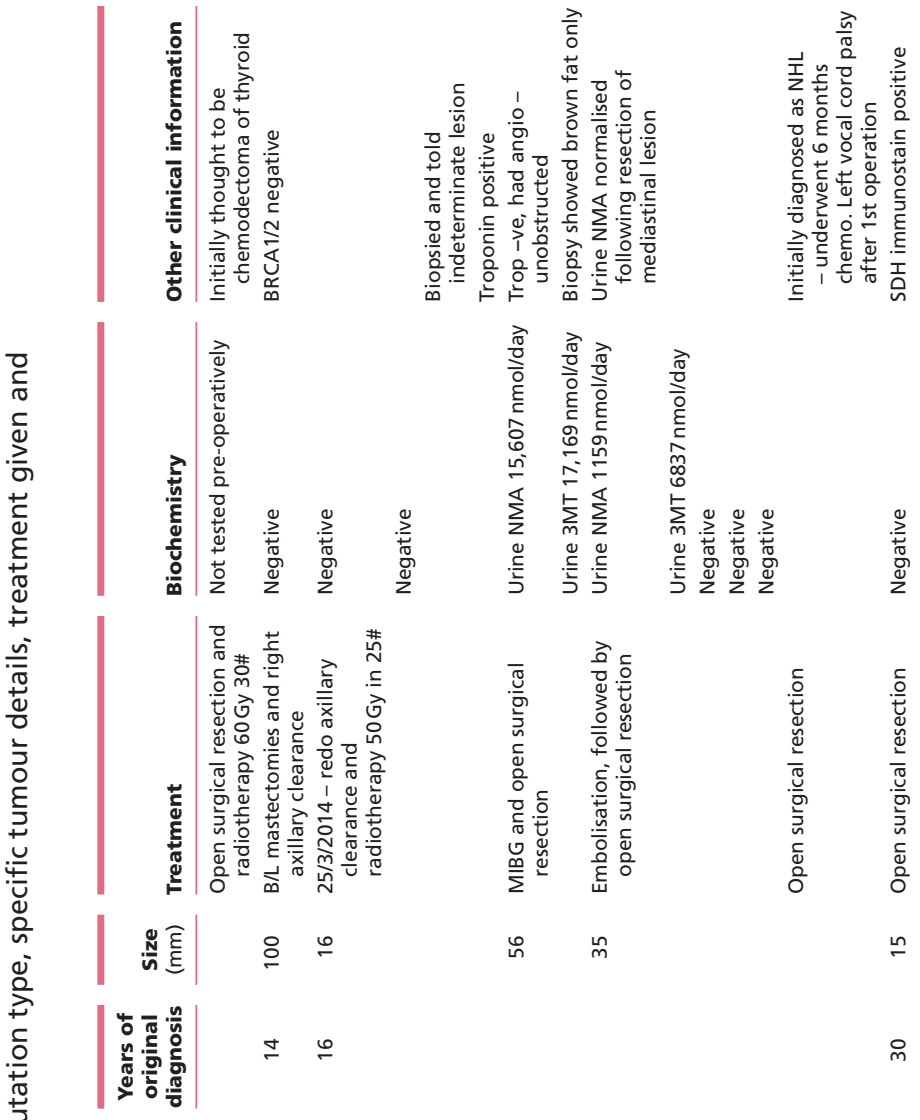

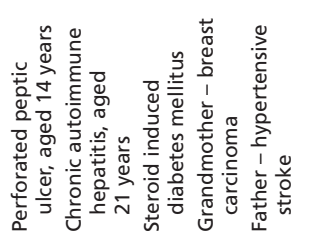

เก $\stackrel{\text { เn }}{m}$
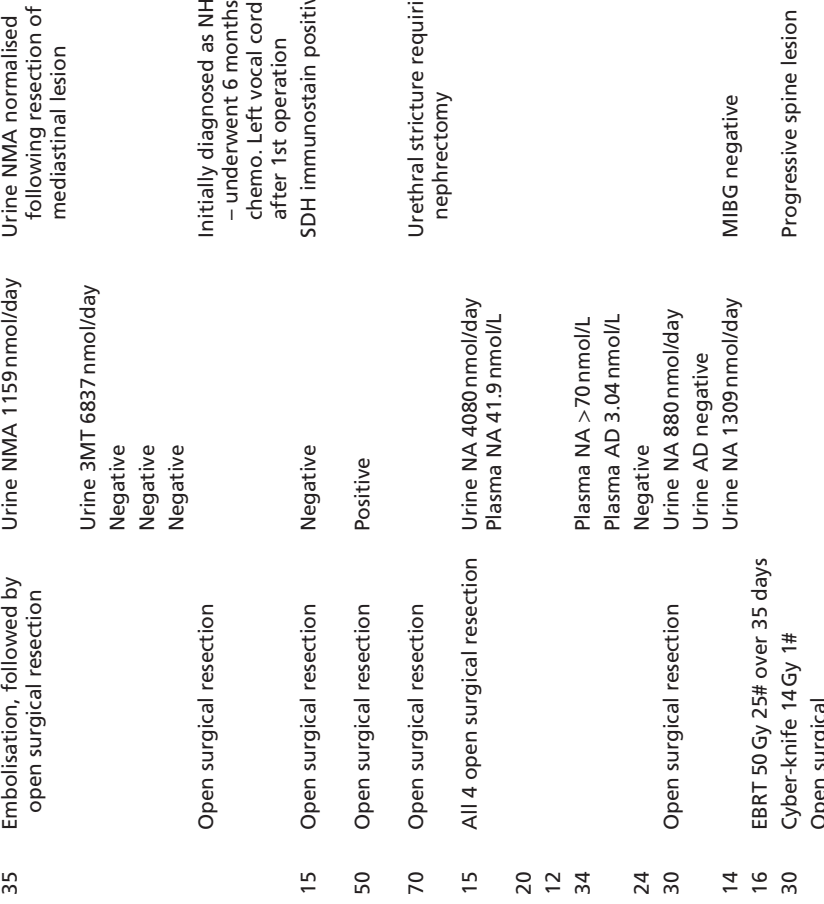

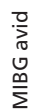
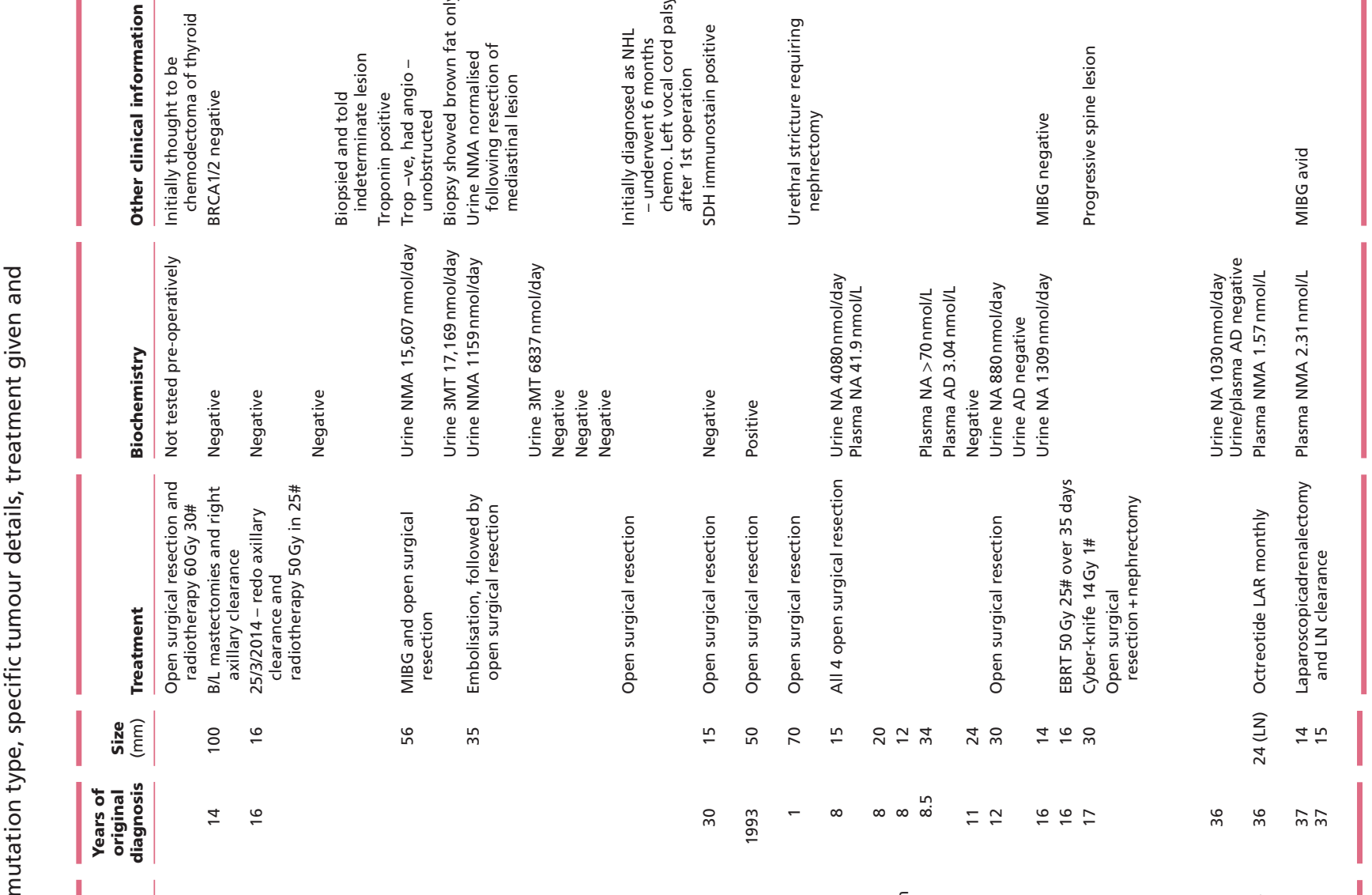


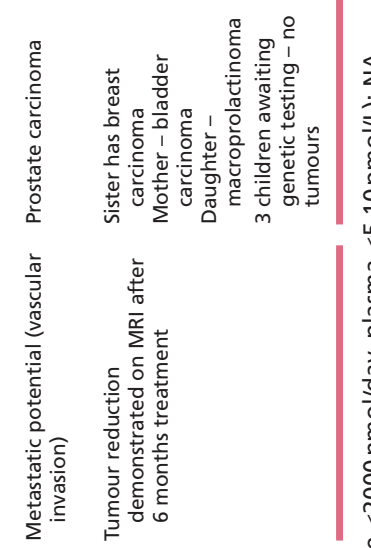

demonstrated on FDG PET. A bone biopsy confirmed a metastatic deposit and he underwent external beam radiotherapy (50Gy 25\#), followed by cyber-knife radiotherapy (14Gy 1\#) when this lesion doubled in size. His metanephrines have remained normal since his radiotherapy six years ago, and the bone lesions have stabilised in size.

Patient 9 presented aged 18 years with a symptomatic phaeochromocytoma in 1973. She underwent an adrenalectomy and nephrectomy, and remained asymptomatic for 36 years until experiencing episodes of hot flushes, hypertension and haematuria. Imaging revealed a lesion in the para-aortic region and metanephrine levels were raised (Table 1). ${ }^{68} \mathrm{Ga}$ DOTATATE PET scan identified metastatic disease in the sacrum and T10 vertebral body with lymph node involvement and she was commenced on Octreotide LAR $30 \mathrm{mg}$ monthly. Most recent surveillance imaging (MRI and MIBG) shows no disease progression, and she has normal biochemistry.

The five asymptomatic carriers identified through cascade screening have not had any tumours identified in surveillance imaging and all have negative biochemistry. They have had a total of 17 years of surveillance. Additionally, patient 8 has one adult son who has been undergoing clinical and radiological screening with no tumours identified to date, but has not yet undergone genetic testing. Patient 11 has three children and one sister (who has breast carcinoma) who are awaiting genetic testing, but have no history of PPGL.

The six index cases described here presented with a variety of clinical manifestations extending the known phenotypic spectrum in SDHA disease.

Little is known about PGL-associated disease in carriers of an SDHA mutation. Table 2 shows the 26 cases reported in the literature with 14 different SDHA mutations (Burnichon et al. 2010, 2012, Korpershoek et al. 2011, Dwight et al. 2013, Welander et al. 2013, Papathomas et al. 2015, von Dobschuetz et al. 2015, Casey et al. 2017). These patients presented aged 12-62 years. Unlike in $S D H B$ and SDHD, in the described combined cases, there is no obvious predilection to any specific body site.

PGLs occurring in the thyroid gland are extremely rare. A recent evaluation of the ENSAT registry identified only five cases of thyroid PGL (prevalence 0.5\%). Four of these patients were subsequently found to have $S D H$ germline mutations (von Dobschuetz et al. 2015). Interestingly, two of these four patients carried a SDHA mutation, but both 
Table 2 Details of the 26 patients with SDHA mutations who developed phaeochromocytoma or paraganglioma, previously reported in the literature.

\begin{tabular}{|c|c|c|}
\hline Reference & SDHA mutation & Age (years) \\
\hline Burnichon et al. (2010) & c. $1765 C>T$ & 32 \\
\hline \multirow[t]{6}{*}{ Korpershoek et al. (2011) } & c.91C > T & 48 \\
\hline & & 41 \\
\hline & & 55 \\
\hline & & 33 \\
\hline & & 45 \\
\hline & & 27 \\
\hline Welander et al. (2013) & c. $223 \mathrm{C}>\mathrm{T}$ & 20 \\
\hline Dwight et al. (2013) & c. $1873 C>T$ & 46 \\
\hline \multirow[t]{2}{*}{ von Dobschuetz et al. (2015) } & c.394T >C & 36 \\
\hline & c. $1799 G>A$ & 37 \\
\hline \multirow[t]{4}{*}{ Papathomas et al. (2015) } & c. $1534 \mathrm{C}>\mathrm{T}$ & 23 \\
\hline & c. $1766 \mathrm{G}>\mathrm{A}$ & 24 \\
\hline & c. $1765 C>T$ & 31 \\
\hline & c. $1753 \mathrm{C}>\mathrm{T}$ & 19 \\
\hline \multirow[t]{11}{*}{ Casey et al. (2017) } & c.91C > T & 56 \\
\hline & & 33 \\
\hline & & 45 \\
\hline & & 15 \\
\hline & c. $923 \mathrm{C}>\mathrm{T}$ & 43 \\
\hline & & 52 \\
\hline & C. $1753 C>T$ & 34 \\
\hline & c. $1273 G>A$ & 62 \\
\hline & c. $133 \mathrm{G}>\mathrm{A}$ & 36 \\
\hline & c. $136 \mathrm{~A}>\mathrm{G}$ & 12 \\
\hline & c.1338delA & 48 \\
\hline
\end{tabular}

\begin{tabular}{c}
\hline Gender \\
\hline$F$ \\
$F$ \\
$M$ \\
$F$ \\
$F$ \\
$M$ \\
$M$ \\
$F$ \\
$F$ \\
$F$ \\
$F$ \\
$M$ \\
$M$ \\
$F$ \\
$F$ \\
$M$ \\
$M$ \\
$M$ \\
$F$ \\
$M$ \\
$M$ \\
$F$ \\
$M$ \\
$M$ \\
$F$ \\
$F$ \\
\hline
\end{tabular}

\begin{tabular}{l} 
Clinical presentation \\
\hline Abdominal PGL \\
Phaeochromocytoma \\
Bladder PGL with local LN spread \\
Thoracic PGL \\
Vagal PGL \\
CBT \\
Abdominal PGL \\
Abdominal PGL \\
CBT* \\
Thyroid PGL \\
Thyroid PGL \\
Abdo PGL with malignant LN spread \\
Phaeochromocytoma \\
Abdo PGL \\
Phaeochromocytoma \\
HNPGL \\
Abdo PGL \\
Abdo PGL \\
PCC \\
Malignant thoracic PGL \\
Bilateral HNPGL+PCC \\
PGL \\
Abdo PGL+ PCC \\
Thoracic PGL \\
Abdo PGL \\
HNPGL
\end{tabular}

*Son had a pituitary adenoma.

Abdo, abdominal; CBT, carotid body tumour; HNPGL, head and neck paraganglioma; LN, lymph node; PCC, phaeochromocytoma; PGL, paraganglioma.

mutations were different to the one our patient carried. Similar to our patient, both were female and presented at similar ages (36 and 37 years), with no family history of PGL.

Recognised associations of SDHA mutations include gastrointestinal stromal tumours (GIST) (Papathomas et al. 2014) and SDHA variants have been described in three patients with pituitary adenomas, although SDHA deficiency was only demonstrated in one tumour by immunohistochemistry (IHC) and loss of heterozygosity (LoH) was not demonstrated (Dwight et al. 2013, O'Toole et al. 2015). To date, only one case of SDHA-deficient renal carcinoma has been reported (Yakirevich et al. 2015). Additional findings in our cohort included: bilateral breast carcinoma 14 years after PGL diagnosis (patient 1). Patient 11's PGL was discovered incidentally during staging imaging for his prostate carcinoma, and he was subsequently found to have a macroprolactinoma. His daughter also has a microprolactinoma, although is awaiting genetic testing.

Two out of six of our index patients have developed distant metastatic PPGLs. Time to disseminated disease was 16 and 37 years, and occurred following development of recurrent disease, suggesting a long duration of disease before onset of metastases.

A cautious approach must be used before ascribing definite pathogenicity to newly identified mutations. Table 3 combines the evidence that suggests pathogenicity for each of the described mutations. SDHA immunohistochemistry (IHC) was performed on tissue that was available. One sample (patient 8) demonstrated positive SDHA IHC. It has previously been described that SDHA IHC maybe positive in the presence of a definitive mutation, but on rare occasions, there is disparity between molecular genetic aberrations of a tumour suppressor gene and retention of protein expression (Miettinen et al. 2013, Evenepoel et al. 2015, Papathomas et al. 2015). It has been hypothesised that this may be due to the second hit in the SDHx gene in the tumour tissue resulting in an inactive SDH complex with preservation of antigenicity (Papathomas et al. 2015).

The mutation carried by this patient (patient 8) had the most aggressive phenotype in our cohort. A recently reported metastatic case carried the same SDHA mutation (Casey et al. 2017). Casey and coworkers went on to 
Table 3 Investigations of pathogenicity for mutation variants.

\begin{tabular}{|c|c|c|c|c|c|}
\hline Pt. No. & Mutation & Type & In silico analysis & $\begin{array}{l}\text { Immunochemistry } \\
\text { analysis }\end{array}$ & $\begin{array}{l}\text { EXAC database } \\
\text { population frequency }\end{array}$ \\
\hline 1 & c. $91 \mathrm{C}>\mathrm{T}$ exon 2 & Frameshift & $\begin{array}{l}\text { ExPASy translate tool } \\
\text { - premature stop } \\
\text { codon resulting in a } \\
\text { truncated protein }\end{array}$ & $\begin{array}{l}\text { PGL tissue unavailable } \\
\text { for analysis. Breast } \\
\text { tissue } \\
\text { immunopositive for } \\
\text { SDHA and SDHB }\end{array}$ & $\begin{array}{l}0.2 \text { per } 1000 \\
\text { individuals (South } \\
\text { Asian population). } \\
0.3 \% \text { of Dutch } \\
\text { controls }\end{array}$ \\
\hline 3 & c.1338delA exon 10 & Frameshift & $\begin{array}{l}\text { ExPASy translate tool: } \\
\text { premature stop } \\
\text { codon resulting in a } \\
\text { truncated protein }\end{array}$ & $\begin{array}{l}\text { PGL immunonegative } \\
\text { for SDHA }\end{array}$ & $\begin{array}{l}<1 \text { per } 1000 \\
\text { individuals } \\
1.499 \mathrm{E}-05\end{array}$ \\
\hline \multirow[t]{2}{*}{7} & c. $1753 C>T$ exon 7 & Missense & $\begin{array}{l}\text { PolyPhen2 } \\
\text { programme with a } \\
\text { score of } 1.000 \\
\text { (damaging) }\end{array}$ & $\begin{array}{l}\text { PGL immunonegative } \\
\text { for SDHA }\end{array}$ & $\begin{array}{r}<1 \text { per } 1000 \\
\text { individuals }\end{array}$ \\
\hline & & & $\begin{array}{l}\text { SIFT programme, with } \\
\text { a score of } 0.00 \\
\text { (deleterious) }\end{array}$ & $\begin{array}{l}\text { Parathyroid tissue } \\
\text { immunopositive for } \\
\text { SDHA }\end{array}$ & 0.0000248 \\
\hline \multirow[t]{2}{*}{8} & c. $923 \mathrm{C}>\mathrm{T}$ exon 8 & Missense & $\begin{array}{l}\text { PolyPhen2 } \\
\text { programme with a } \\
\text { score of } 1.000 \\
\text { (damaging) }\end{array}$ & $\begin{array}{l}\text { PGL tissue unavailable } \\
\text { for analysis }\end{array}$ & Not reported \\
\hline & & & $\begin{array}{l}\text { SIFT programme, with } \\
\text { a score of } 0.00 \\
\text { (deleterious) }\end{array}$ & $\begin{array}{l}\text { Tissue specimen from } \\
\text { bone biopsy } \\
\text { immunopositive for } \\
\text { SDHA and } \\
\text { heterogenous SDHB } \\
\text { immunochemistry. } \\
\text { Not enough tissue } \\
\text { available for LoH } \\
\text { analysis }\end{array}$ & \\
\hline 9 & c.91C>T exon 2 & Frameshift & $\begin{array}{l}\text { ExPASY translate tool } \\
\text { - premature stop } \\
\text { codon resulting in a } \\
\text { truncated protein }\end{array}$ & $\begin{array}{l}\text { PGL tissue unavailable } \\
\text { for analysis }\end{array}$ & $\begin{array}{r}0.2 \text { per } 1000 \\
\text { individuals }\end{array}$ \\
\hline 11 & c.91C > T exon 2 & Frameshift & $\begin{array}{l}\text { ExPASY translate tool } \\
\text { - premature stop } \\
\text { codon resulting in a } \\
\text { truncated protein }\end{array}$ & $\begin{array}{l}\text { PGL tissue unavailable } \\
\text { for analysis }\end{array}$ & $\begin{array}{l}0.2 \text { per } 1000 \\
\text { individuals }\end{array}$ \\
\hline
\end{tabular}

\author{
Published reports \\ on pathogenicity \\ Korpershoek et al. \\ (2011)
}

Casey et al. (2017)

Casey et al. (2017)

Korpershoek et al. (2011)

Casey et al. (2017) Papathomas et al. (2015)

Casey et al. (2017)

Korpershoek et al. (2011)

Casey et al. (2017) Korpershoek et al (2011)

Casey et al. (2017)

In silico analyses were performed on each missense mutation using programmes SIFT and PolyPhen2 in order to predict pathogenicity of the DNA variants. The mutations were classified as probably damaging by PolyPhen2 programme with a score of 1.000 (scores $0.0-1.00$, with the most damaging at 1.000), (sensitivity 0.00 ; specificity 1.00 ) and classified as deleterious by SIFT programme with a score of 0.00 (scores $0.0-1.0$, with the most damaging at 0.0 ). Column five shows immunohistochemistry analysis of tissue (where available). Column six shows population frequency from the EXAC database and references for where mutations have been previously published are shown in the last column.

perform structural analysis of the effects of this mutation (using DUET scoring) and predicted that it would cause mild destabilisation of the protein promoter region and part of the substrate-binding region and therefore likely to affect protein stability. This may explain the positive protein expression seen in patient 8 .

The patients we report highlight a more diverse and expanding clinical spectrum of SDHA-associated phenotypes. Of our six index cases, two developed metastatic disease and a further one had local vascular invasion. There are three previous reported metastatic cases in the literature (Table 2) with three different SDHA mutations. Interestingly, the two metastatic cases we report each carry one of these mutations (Korpershoek et al. 2011, Papathomas et al. 2015, Casey et al. 2017). With five of the 32 reported cases developing metastatic disease, we suggest that SDHA-related disease is therefore not seen as a low-risk condition.

We believe, with the current uncertainty about pathogenicity and penetrance, these patients should be part of a surveillance programme to monitor for metachronous and metastatic disease. Very few familial 
cases have been reported and none of our asymptomatic carriers have developed tumours. This raises questions about cascade genetic screening and subsequent clinical surveillance. However, given the recognition of aggressive behaviour in SDHA, we believe these relatives should be monitored in surveillance programmes until the full phenotype and penetrance are established.

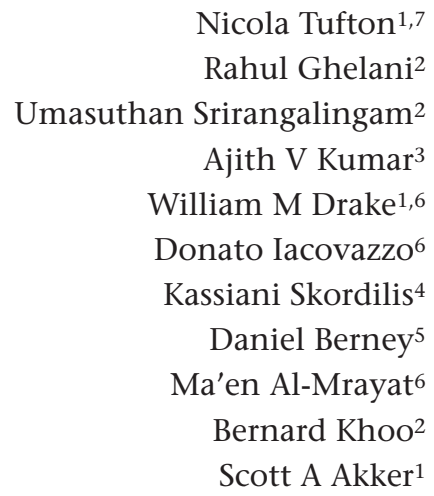

1Department of Endocrinology, St Bartholomew's Hospital, Barts Health NHS Trust, West Smithfield, London, UK ${ }^{2}$ Department of Endocrinology, Royal Free Hospital, Hampstead, London, UK

${ }^{3}$ North East Thames Regional Genetics Service, Great Ormond Street Hospital, London, UK ${ }^{4}$ Department of Histopathology, Queen Elizabeth Hospital, University Hospital Birmingham NHS Foundation Trust, Birmingham, UK

${ }^{5}$ Department of Histopathology, St Bartholomew's Hospital, Barts Health NHS Trust, West Smithfield, London, UK

${ }^{6}$ Department of Endocrinology, Southampton General Hospital, University Hospital Southampton NHS Trust, Southampton, Hampshire, UK ${ }^{7}$ Centre for Endocrinology, Barts and The London School of Medicine and Dentistry, Queen Mary University of London, Charterhouse Square, London, UK

(Correspondence should be addressed to S A Akker; email: S.a.akker@qmul.ac.uk)

\section{Declaration of interest}

The authors declare that there is no conflict of interest that could be perceived as prejudicing the impartiality of this article.

\section{Funding}

N T is funded by The Medical College of Saint Bartholomew's Hospital Trust (1115519).

\section{Acknowledgements}

This study was carried out in accordance with the Declaration of Helsinki and all the applicable local regulations. As this is an analysis on subjects' data taken during normal clinical practice, no specific authorization by ethic committee was sought.

\section{References}

Benn DE, Robinson BG \& Clifton-Bligh RJ 201515 years of paraganglioma: clinical manifestations of paraganglioma syndromes types 1-5. Endocrine-Related Cancer 22 T91-T103. (doi:10.1530/ERC15-0268)

Bourgeron T, Rustin P, Chretien D, Birch-Machin M, Bourgeois M, Viegas-Pequignot E, Munnich A \& Rotig A 1995 Mutation of a nuclear succinate dehydrogenase gene results in mitochondrial respiratory chain deficiency. Nature Genetics 11 144-149. (doi:10.1038/ng1095-144)

Burnichon N, Briere JJ, Libe R, Vescovo L, Riviere J, Tissier F, Jouanno E, Jeunemaitre X, Benit P, Tzagoloff A, et al. 2010 SDHA is a tumor suppressor gene causing paraganglioma. Human Molecular Genetics 19 3011-3020. (doi:10.1093/hmg/ddq206)

Burnichon N, Cascon A, Schiavi F, Morales NP, Comino-Mendez I, Abermil N, Inglada-Perez L, de Cubas AA, Amar L, Barontini M, et al. 2012 MAX mutations cause hereditary and sporadic pheochromocytoma and paraganglioma. Clinical Cancer Research 18 2828-2837. (doi:10.1158/1078-0432.CCR-12-0160)

Casey RT, Ascher DB, Rattenberry E, Izatt L, Andrews KA, Simpson HL, Challis B, Park S-M, Bulusu VR, Lalloo F, et al. 2017 SDHA related tumorigenesis: a new case series and literature review for variant interpretation and pathogenicity. Molecular Genetics and Genomic Medicine 5 237-250. (doi:10.1002/mgg3.279)

Dwight T, Mann K, Benn DE, Robinson BG, McKelvie P, Gill AJ, Winship I \& Clifton-Bligh RJ 2013 Familial SDHA mutation associated with pituitary adenoma and pheochromocytoma/ paraganglioma. Journal of Clinical Endocrinology and Metabolism 98 E1103-E1108. (doi:10.1210/jc.2013-1400)

Evenepoel L, Papathomas TG, Krol N, Korpershoek E, de Krijger RR, Persu A \& Dinjens WN 2015 Toward an improved definition of the genetic and tumor spectrum associated with SDH germ-line mutations. Genetics in Medicine 17 610-620. (doi:10.1038/gim.2014.162)

Korpershoek E, Favier J, Gaal J, Burnichon N, van Gessel B, Oudijk L, Badoual C, Gadessaud N, Venisse A, Bayley JP, et al. 2011 SDHA immunohistochemistry detects germline SDHA gene mutations in apparently sporadic paragangliomas and pheochromocytomas. Journal of Clinical Endocrinology and Metabolism 96 E1472-E1476. (doi:10.1210/jc.2011-1043)

Miettinen M, Killian JK, Wang ZF, Lasota J, Lau C, Jones L, Walker R, Pineda M, Zhu YJ, Kim SY, et al. 2013 Immunohistochemical loss of succinate dehydrogenase subunit A (SDHA) in gastrointestinal stromal tumors (GISTs) signals SDHA germline mutation. American Journal of Surgical Pathology 37 234-240. (doi:10.1097/ PAS.0b013e3182671178)

O’Toole SM, Denes J, Robledo M, Stratakis CA \& Korbonits M 201515 years of paraganglioma: the association of pituitary adenomas and phaeochromocytomas or paragangliomas. Endocrine-Related Cancer 22 T105-T122. (doi:10.1530/erc-15-0241)

Papathomas TG, Gaal J, Corssmit EP, Oudijk L, Korpershoek E, Heimdal K, Bayley JP, Morreau H, van Dooren M, Papaspyrou $\mathrm{K}$, et al. 2014 Non-pheochromocytoma (PCC)/paraganglioma (PGL) tumors in patients with succinate dehydrogenase-related PCC-PGL syndromes: a clinicopathological and molecular analysis. European Journal of Endocrinology 170 1-12. (doi:10.1530/EJE-13-0623)

Papathomas TG, Oudijk L, Persu A, Gill AJ, van Nederveen F, Tischler AS, Tissier F, Volante M, Matias-Guiu X, Smid M, et al. 2015

Published by Bioscientifica Ltd. 
SDHB/SDHA immunohistochemistry in pheochromocytomas and paragangliomas: a multicenter interobserver variation analysis using virtual microscopy: a Multinational Study of the European Network for the Study of Adrenal Tumors (ENS@T). Modern Pathology 28 807-821. (doi:10.1038/modpathol.2015.41)

Renkema GH, Wortmann SB, Smeets RJ, Venselaar H, Antoine M, Visser G, Ben-Omran T, van den Heuvel LP, Timmers HJ, Smeitink JA, et al. 2015 SDHA mutations causing a multisystem mitochondrial disease: novel mutations and genetic overlap with hereditary tumors. European Journal of Human Genetics 23 202-209. (doi:10.1038/ejhg.2014.80)

von Dobschuetz E, Leijon H, Schalin-Jantti C, Schiavi F, Brauckhoff M, Peczkowska M, Spiazzi G, Dematte S, Cecchini ME, Sartorato P, et al.
2015 A registry-based study of thyroid paraganglioma: histological and genetic characteristics. Endocrine-Related Cancer 22 191-204. (doi:10.1530/ERC-14-0558)

Welander J, Garvin S, Bohnmark R, Isaksson L, Wiseman RW, Soderkvist P \& Gimm O 2013 Germline SDHA mutation detected by next-generation sequencing in a young index patient with large paraganglioma. Journal of Clinical Endocrinology and Metabolism 98 E1379-E1380. (doi:10.1210/jc.2013-1963)

Yakirevich E, Ali SM, Mega A, McMahon C, Brodsky AS, Ross JS, Allen J, Elvin JA, Safran H \& Resnick MB 2015 A novel SDHA-deficient renal cell carcinoma revealed by comprehensive genomic profiling. American Journal of Surgical Pathology 39 858-863. (doi:10.1097/ PAS.0000000000000403)

Received in final form 2 May 2017

Accepted 12 May 2017

Accepted Preprint published online 12 May 2017
Published by Bioscientifica Ltd. 